\title{
A ideia de nação em Marcel Mauss
}

Daniel de Oliveira Rodrigues Gomes

MAUSS, M. A nação. São Paulo: Três Estrelas, 2017.

A nação é uma coletânea de textos em que o antropólogo Marcel Mauss define essa forma de comunidade humana posta em grande relevo pela Primeira Guerra Mundial, abordando ainda sua relação com o socialismo, com os direitos dos cidadãos e com a utopia internacionalista. Escritos entre 1919 e 1930, alguns desses textos foram publicados em jornais e revistas socialistas, como estímulo à formação política de militantes e ao cooperativismo trabalhista; outros permaneceram por muito desconhecidos, como planos de uma futura obra jamais consolidada pelo discípulo e sobrinho de Émile Durkheim. Somente em 2013, ocorre a primeira reunião desses artigos numa edição francesa, enquanto a brasileira vem à tona em 2017.

O livro conta com rica apresentação de Jean Terrier ${ }^{1}$ e Marcel Fournier, ${ }^{2}$ que o contextualizam histórica, política e biograficamente, enfatizando que $A$ nação se conecta ao famoso Ensaio sobre a Dádiva pela ideia fundamental de "troca". Para Mauss (2017, p. 99), não há como pensar os indivíduos e os grupos sociais sem seus intercâmbios, nem a nação fora das relações internacionais: “É, de fato, uma abstração julgar que a politica interna de uma nação não é amplamente condicionada pelo exterior, e vice-versa".

1 Doutor em Ciência Política e Social pelo European University Institute. Professor de Ciência Política na Universidade de Münster.

2 Doutor em Sociologia pela École Pratique de Hautes Études (Paris). Professor de Sociologia da Universidade de Montreal.

\section{Daniel de Oliveira Rodrigues Gomes}

Bacharel em Ciências Sociais pela UECE. Mestre em Sociologia pela UFC. Doutorando em Sociologia pela UECE. Sociólogo da Defensoria Pública da União em Fortaleza, Ceará. E - mail: danielorg@yahoo.com.br. 
A nação se estrutura em três grandes partes, precedidas de texto mais curto em que Mauss expõe o projeto e o fio condutor da obra. Organizam-se na seguinte ordem: "A nação ou O sentido do social" (preâmbulo); "Da nação como gênero de sociedade" (parte I); "As relações internacionais ou Do internacionalismo" (parte II); e "Das nacionalizações ou Do socialismo" (parte III). Ao fim dessas partes, encontra-se ainda um texto complementar, denominado "O princípio das nacionalidades", em que o autor sintetiza os argumentos desenvolvidos anteriormente.

Na seção introdutória, Mauss (2017, p. 47) delimita o caráter moderno de seu objeto de estudo: "as formas mais recentes de sociedade, as nações, as mais avançadas das sociedades conhecidas". Situa-o no campo da política, ressalvando que não pretende traçar leis sociais gerais (como teriam feito Maquiavel, Comte e Rousseau), mas compreender em sentido histórico as nações, que não considera as primeiras nem as últimas formas de sociedade, tampouco as mais naturais ou ideais.

Também acautelando que não se pode definir as nações a partir de "supostos critérios de nacionalidade", como "raça", "língua" e "civilização" (MAUSS, 2017, p. 48), o autor argumenta que a conceituação se relaciona com três princípios políticos modernos. São eles: o "individualismo", que entende como a emancipação dos cidadãos das antigas tiranias (reais, imperiais, religiosas e até populares) e a formação da nação em oposição ao Estado; o "internacionalismo", que consiste nas relações entre nações, cuja melhor compreensão histórico-comparativa permitiria a afirmação de contatos cada vez mais pacíficos; e o "socialismo", entendido como processo pelo qual "as nações tendem a se tornar senhoras, se não de toda a economia, pelo menos da parte da economia que é de seu domínio próprio" (MAUSS, 2017, p. 49). A questão do individualismo foi a única não desenvolvida no livro.

Após definir a nação na parte I do livro, o autor trata do internacionalismo e do socialismo, respectivamente, nas suas partes II e III. Desde o início da obra, é possível observar a utopia maussiana que a move: o aprofundamento científico-social sobre a nação permitiria traçar melhores rumos para a política, vista como "uma 
espécie de psiquiatra. Precisamos, portanto, reeducar essa alma" (MAUSS, 2017, p. 53).

Na parte I, Mauss (2017) inicia um breve resgate histórico dos usos do termo "nação", defendendo que ele ganha sentido mais preciso com a Revolução Francesa e o estabelecimento do dia da Federação, quando "uma nação procura tomar consciência de si mesma, por meio de ritos, de uma festa, e manifestar-se perante o poder do Estado" (MAUSS, 2017, p. 59). Contudo, argumenta que essa consciência, por ser muito revolucionária, foi abandonada por teóricos da política e do direito (internacional, constitucional e civil), que, ao longo do século XIX, preferiram referir-se ao termo "Estado". O antropólogo lembra ainda Ernest Renan, quando afirma que nesse período ainda deveriam ser criadas nações de fato. Somente após a Revolução Russa, a palavra "nação" tornaria a ganhar força, embora isso não tenha se traduzido em teorizações à altura.

Nesse sentido, o autor passa a discorrer sobre o conceito de nação. Esta é diferenciada de grupos polissegmentares e de sociedades tribais: os primeiros dividem-se em coletividades políticas familiares, sem poder central nem organização constante; de certo modo, estes fatores passam a existir nas segundas, onde a divisão em clãs ainda expressa uma solidariedade frouxa e insensível quanto às fronteiras e à organização social interna, podendo a tribo até mesmo ser governada por tiranos estrangeiros. Em suma, ambos os tipos de agrupamentos "podem se deixar amputar, maltratar, decapitar até" (MAUSS, 2017, p. 68). ${ }^{3}$

Somente com o desaparecimento dos clãs, a estabilidade sócio-organizativa e o exercício democrático do poder, característicos de "sociedades integradas", ${ }^{4}$ haveria pré-condições para o surgi-

3 Como exemplos de grupos polissegmentares, Mauss (2017, p. 65) cita "Israel antes de entrar em Canaã" e "Os futuros romanos antes da fundação de Roma, os antigos germânicos". Já como sociedades tribais, ele se refere a: zulus e bagandas na África do Sul; tribos democratizadas do Congo e do Loango; algonquinos, sioux e iroqueses na América do Norte; e malaios, nigricianos, nilóticos e tribos chinesas do Annam.

4 O termo "sociedades integradas" é emprestado de Herbert Spencer, conforme esclarecido por Mauss (2017). Tais sociedades já se encontrariam na China e no Egito antigos, bem como "nas da Grécia mais primitivas" e "na América précolombiana [...] Central e Andina" (MAUSS, 2017, p. 67). 
mento da nação. Esta é definida como "uma sociedade material e moralmente integrada, com poder central estável, permanentemente, fronteiras definidas, relativa unidade moral, mental e cultural dos habitantes, os quais aderem conscientemente ao Estado e suas leis" (MAUSS, 2017, p. 70).

Mauss (2017) reconhece que esse conceito só se aplicaria a um pequeno número de sociedades à sua época, que "estão longe de ser da mesma natureza e de estar no mesmo estágio da evolução" (MAUSS, 2017, p. 71 - grifo meu). Nessa perspectiva evolucionista, enumera vários exemplos que ainda "não merecem" o título de nação, embora Brasil, Argentina e Chile sejam destacados como "Estados de tipo europeu e já são jovens nações" (MAUSS, 2017, p. 71), pois teriam ultrapassado "estágios da tirania, da oligarquia e das formas primitivas de Estado" (MAUSS, 2017, p. 73). Nisso, contribuiria ainda a presença significativa de europeus entre a população mestiça, o que pode significar que o autor acaba por inserir fatores biológicos ou "raciais" na compreensão da nação, argumento repetido ao longo da obra, apesar de suas críticas anteriores.

Em realidade, para Mauss (2017, p. 75), somente a França - sua terra natal - e os Estados Unidos - incompreensivelmente classificado como "a nação menos imperialista" - haviam alcançado o estágio mais elevado da evolução nacional. Isso leva a indagar: à época, poderiam mesmo ambos os países ser considerados moral, mental e culturalmente integrados, se no primeiro se discriminavam os imigrantes das colônias e no segundo se marginalizava a população negra?

De todo modo, o autor acrescenta que a comunidade nacional é a unidade econômica humana mais extensa conhecida, tendo a ideia de nação sido indispensável à superação dos círculos de troca provinciais e municipais. A própria integração da economia mundial, apesar dos protecionismos alfandegários, demanda segundo Mauss (2017, p. 77) esse tipo de agrupamento humano: "Todas as concepções do mais avançado internacionalismo econômico pressupõem, no fundo, essa comunidade nacional e essa rivalidade de interesses entre nações".

Um dos pontos mais promissores do livro concerne à cidadania, vista como sustentáculo da soberania nacional. A participação 
do cidadão na administração pública, por delegação parlamentar, é considerada pré-condição fundamental da nação, diferenciando-a do Antigo Regime. Trata-se de uma integração consciente dos indivíduos à vida política, pensada a partir dos filósofos contratualistas e que passa a ser trabalhada obrigatoriamente pela escola pública, com vistas ao progresso coletivo.

Contudo, essa contribuição resta prejudicada pela contraditória atitude de traçar, para a comunidade nacional, supostas fronteiras objetivas - e não imaginadas, como proposto por Anderson (2005), por exemplo. Apegando-se a uma ideia essencialista e até naturalista de "caráter nacional", Mauss (2017) afirma que, numa nação completa, os indivíduos estariam circunscritos a uma raça, uma civilização, uma língua e uma moral. Veja-se:

[...] uma nação completa é uma sociedade suficientemente integrada, com poder central democrático em algum grau, que tem, em todo caso, a noção de soberania nacional e cujas fronteiras, em geral, são as de uma raça, de uma civilização, de uma língua, de uma moral - em uma palavra, de um caráter nacional. Podem faltar alguns elementos. [...] Nas nações acabadas, porém, todos eles coincidem. Essas coincidências são raras, e por isso mesmo são ainda mais notáveis e, se nos for permitido julgar, mais belas. Pois, mesmo sem preconceitos polítiCos, é possível julgar sociedades, assim como julgamos os animais e as plantas (MAUSS, 2017, p.92 - grifos meus).

Na parte II, sob influência do conceito durkheimiano de "fato social", ${ }^{5}$ Mauss (2017) trata das relações internacionais. Divide-as em três tipos de fatos ou fenômenos: internacionais ou intersociais, morfológicos e ideais. Os primeiros dizem respeito à humanidade como grande palco de trocas materiais e imateriais entre as sociedades. Estas, como os indivíduos, formam-se nos contatos

5 Segundo Durkheim (2003, p. 13): "É fato social toda maneira de fazer, fixada ou não, suscetível de exercer sobre o indivíduo uma coerção exterior; ou ainda, toda maneira de fazer que é geral na extensão de uma sociedade dada e, ao mesmo tempo, possui existência própria, independente de suas manifestações individuais". 
entre si: "Tudo o que é social e não da própria constituição da sociedade pode ser emprestado de uma nação, de uma sociedade a outra" (MAUSS, 2017, p. 101). Isso implica haver comércio não apenas na economia, mas nos empréstimos de tecnologias constatadas como superiores (notoriamente na área militar), de ciências, de belas artes, de religiões, de concepções jurídicas e de línguas - cerca de um terço do vocabulário moderno, segundo o autor, seria supranacional (MAUSS, 2017).

Já os fenômenos morfológicos se relacionam às estruturas que possibilitam as trocas intersociais, cada vez mais amplas e densas na modernidade. Como exemplos, o autor cita de modo eloquente: a navegação, com profundo impacto na vida entre os povos - "Todos aspiram à água, ao espaço marítimo, a se tornar seres planetários e não apenas europeus ou americanos" (MAUSS, 2017, p. 122); as estradas; os meios de comunicação telegráficos, telefônicos e postais - "É como se as grandes nações tivessem criado para si uma voz e um ouvido de alcance infinito" (MAUSS, 2017, p. 124); e povos dispersos, mercadores, colonos - esses três primeiros classificados como "poderosos fermentos de progresso e civilização" (MAUSS, 2017, p. 126) -, soldados, artistas, filósofos, viajantes, mercenários, judeus, ciganos, tribos migrantes africanas e asiáticas e nações colonizadoras - estas, "autênticos meios sociais, cosmopolitas por assim dizer, em que as pessoas são cidadãos de toda parte e da própria Terra" (MAUSS, 2017, p. 127).

A guerra e a colonização (um dos três tipos de subordinação social, além da dominação militar e da anexação) são os fatos morfológicos mais destacados por Mauss (2017). A primeira seria fenômeno sociológico pouco analisado em sua natureza e não somente em suas consequências, restando "saber por que o homem é o único animal que mata regularmente seu semelhante; e por que ele acredita que deve matar" (MAUSS, 2017, p.129). Embora constate que seja tão antiga quanto a humanidade, o autor propõe que a guerra mais recentemente gera consciência de si às nações: "As nações se construíram na, pela e para a guerra. O momento decisivo foi o das guerras da Revolução" (MAUSS, 2017, p.134). Em adendo, afirma que a França teria inventado o exército nacional, o que talvez possa ser relativizado a partir da proposta 
de substituição de tropas mercenárias por exércitos de cidadãos em Maquiavel (2011).

A colonização, fenômeno também antigo da humanidade, dá-se de três modos: por povoamento, quando a sociedade colonizadora se transporta ao novo território para viver à sua maneira, provocando o desaparecimento da "raça inferior" por doenças ou lutas especialmente sangrentas; por meio da exploração, na qual a "mãe-pátria" envia algumas pessoas para explorar territórios e populações indígenas; e por via administrativa, quando o "Estado soberano" manda apenas coletores de tributos e gestores de vantagens comerciais (MAUSS, 2017, p. 142). Apesar de notar o evidente genocídio muitas vezes implicado na atividade colonizadora, Mauss (2017) defende etnocentricamente que ela teria levado avanços aos dominados:

\begin{abstract}
Para alguma coisa serve a desgraça. Afinal, sempre é [melhor], pra os marroquinos, serem governados por franceses do que por caïds e, para o árabe, estar sob a égide inglesa do que sob a turca. Quaisquer que sejam os crimes, a colonização imperialista fez retroceder a barbárie, a guerra, a escravidão, a miséria em parcelas significativas do globo terrestre. A agregação, mesmo indireta, a grandes nações sobretudo nos casos de desenvolvimento moral destas últimas - é uma garantia de paz, educação, emancipação para povos menos explorados por nós que por seus tiranos (MAUSS, 2017, p.145 -- grifos meus).
\end{abstract}

Por fim, como terceiro tipo de fato intersocial, o autor cita os fenômenos ideais. Trata-se de teorias, doutrinas e movimentos que refletem a interdependência entre as sociedades, como o direito internacional privado (que regula relações entre cidadãos dos Estados) e o público (que regula das relações entre Estados), sendo este capaz de transformar o estrangeiro em cidadão com plenos direitos civis; o cristianismo, como contexto de desenvolvimento do direito internacional, dos movimentos políticos entre os séculos XI e XV na Europa ocidental e da educação uniforme por meio das universidades, nas quais teria se desenvolvido "o próprio 
conceito de nação" (MAUSS, 2017, p. 164); e o internacionalismo operário, "fato [social] absolutamente moderno", que, ao contrário do que ainda hoje pensa o senso corrente, influenciou movimentos socialistas "profundamente nacionais, nacionalistas até", a exemplo da Comuna de Paris (MAUSS, 2017, p.167 - grifos meus).

Nesse ponto, as reflexões de Mauss (2017) oferecem importantes insights aos que estudam as conexões entre marxismo e nacionalismo. Pontuando que o internacionalismo operário nasce com o Manifesto Comunista, Mauss (2017) argumenta que a disseminação da união proletária mundial (MARX; ENGELS, 1998) obteve sucesso por expor que a defesa dos operários em relação ao capital deveria ser tanto internacional quanto nacional. Neste último contexto, lembra que Karl Marx e Friedrich Engels teriam corrigido, ao longo da militância, a errônea ideia de que os operários não teriam pátria (influência do comunismo utópico e anárquico); a conquista do sufrágio universal ter-lhes-ia assinalado que "a revolução social pode se efetuar por meios políticos em todas as esferas da nação" (MAUSS, 2017, p. 169). Entre avanços e recuos, Mauss (2017) cita que essa conexão entre o nacional e o internacional gerou as Internacionais Comunistas, a Aliança Cooperativa Internacional e a Organização Internacional do Trabalho (OIT).

Para o autor, a problemática do apoio em massa dos socialistas à Primeira Grande Guerra seria explicada por uma "imperfeição do internacionalismo operário": compõe-se de movimentos de uma única classe, que não é a mais poderosa e numerosa em muitas nações, só obtendo força quando seus partidos são tão ou mais patriotas que os conservadores. Contudo, a linha entre a defesa da nação e a agressão aos camaradas estrangeiros seria muito tênue, no que o bolchevismo russo é classificado como "estritamente militarista, nacionalista e até panrusso" (MAUSS, 2017, p. 173). Aliás, Mauss (2017), na maior parte das vezes, revela-se extremamente cético quanto aos rumos tomados pela Revolução Russa, que, tal como o fascismo, considera um retorno ao estágio social do tribalismo.

Essas reflexões se conectam à parte III do livro, em que Mauss (2017) trata do socialismo como processo de nacionalização. 
Mais uma vez retoma Durkheim, para quem as teorias socialistas expressariam a vinculação crescente e funcional da economia com os órgãos dirigentes e conscientes da sociedade. Dessa forma, o socialismo não seria pensamento especificamente operário, pois, no fundo, tematizaria a regulação social da economia pelo corpo da nação, ideia que remontaria à fundação da doutrina pelo Conde de Saint-Simon. Assim, o autor propõe a seguinte definição de socialismo:

Entendemos por socialismo ideias, forças, grupos que tendem, em uma nação moderna, a regular o conjunto da vida econômica. Esse processo se opera pela nacionalização, ou seja, pela instauração da propriedade industrial e comercial controlada pela nação, pela instauração de uma forma de propriedade coletiva apropriada para as diversas coletividades que compõem a nação e que dela são atualmente mais ou menos privada (MAUSS, 2017, p. 193).

Com base nessa concepção, Mauss (2017) empreende uma periodização histórica do pensamento socialista. Discorre sobre Saint-Simon, Charles Fourier, Robert Owen, Pierre Leroux, Proudhon e Marx, enfatizando os avanços e limites teóricos de cada um. Em comum, tais autores exprimiriam como o socialismo se relaciona à experiência das nações, pois "não era possível antes de estas terem se formado, ou seja, antes de a noção de pátria como coisa pública se tornar o fundamento do direito púbico e do indivíduo com direitos sobre tudo o que é público" (MAUSS, 2017, p. 214). Disso decorreria, tornando ao tom evolucionista, que "as sociedades que não são nações devem vir a sê-lo antes de se tornarem repúblicas sociais" (MAUSS, 2017, p. 214), o que valeria especialmente para a Rússia, sociedade à qual o autor anteriormente dedicara cerca de sete páginas para tentar provar que ainda não seria uma nação.

Obviamente, o capitalismo não deixa de ser considerado parte do processo de nacionalização. As constituições de sociedades anônimas, trustes, cartéis, barreiras alfandegárias, concessões e tarifas representariam um "movimento politicamente vindo de cima: a tomada de consciência e de direção dos serviços 
econômicos da nação" (MAUSS, 2017, p. 221). As regulamentações e a organização de serviços em domínios públicos demonstraria que o capital não seria "tão anárquico nem tão privado" (MAUSS, 2017, p. 247), embora sua nacionalização progressiva não tendesse à estatização.

Nesse limite do capital, influiria o "movimento econômico de baixo para cima", constituído pelos "movimentos das massas para criar suas próprias instituições" (MAUSS, 2017, p. 249). Caracterizados pela espontaneidade, livre associação e autoajuda dos trabalhadores, esses movimentos se organizariam em sindicatos, cooperativas, partidos políticos e nas lutas pela previdência pública, todos convergindo numa perspectiva de "democracia operária". Mauss (2017), então, passa em revista a história dos movimentos trabalhistas, desde as antigas corporações até o período pós-guerra, quando surge a ideia ainda imatura de um mundo novo ou uma nova ordem, ${ }^{6}$ isto é, do exercício do controle operário da indústria. Nisto se galvanizaria o aprendizado das vantagens da ação coletiva proporcionado pela guerra, quando os operários retornados à vida civil passariam a organizar-se nos terrenos de concentração, as fábricas.

A leitura de A nação chama a atenção por se tratar do esforço, pouco empreendido pelos socialistas daquela época, em apreender de maneira aprofundada esse tipo de comunidade moderna que tanto mobiliza sentimentos, doutrinas e ações políticas de massa, seja pelo viés dos grandes confrontos bélicos, seja pelo da cidadania. É notória a semelhança das ideias de Mauss (2017) com as do austromarxista Otto Bauer (1979), cujo pensamento não resta claro se o antropólogo de fato conhecia: salta aos olhos a ideia comum de que socialismo, ao estender o acesso aos bens culturais e materiais às massas, permitiria que as nações se desenvolvessem como comunidades plenas; como também a noção de que o exército e a escola pública conformam a figura do cidadão;

6 Mauss relembra que a "nova ordem" era uma das classificações do socialismo manejada pelos italianos. Tratava-se também do jornal homônimo encabeçado por Gramsci em Turim, entre 1918 e 1920, quando os operários setentrionais italianos se organizaram aos milhares em Conselhos de Fábrica. 
e, não menos importante, a surpreendente complementaridade entre nacionalismo e internacionalismo, que, embora ainda vistos como opostos extremos por muitos marxistas, é identificada especificamente por Mauss (2017) nas raízes históricas do socialismo.

Contudo, esse rico conhecimento acaba obstaculizado pela limitada conceituação de nação. Inicialmente, Mauss (2017) dá entender que a nação se integraria em sentido eminentemente político e cultural, mas logo insere critérios de raça, língua, civilização e moral, cuja junção formaria a não menos questionável concepção de nação completa ou acabada. Ora, uma perspectiva teórica partilhada por diversos autores em Tensões Mundiais é a de que não é possível analisar as comunidades nacionais simplesmente através de aspectos supostamente objetivos, mas sobretudo por meio de fatores subjetivos. Por conseguinte, não há como demarcar quando esse grupo humano se encontra finalizado, o que aliás seria decretar o fim da história e do imaginário. Certamente, a nação não é a primeira nem a última forma de coletividade, como chega a reconhecer o autor, até hoje permanecendo em pleno vigor e ainda sem "substituto" à altura.

Apesar dessa conceituação hermética e evolucionista, bem como do fato de Marcel Mauss ser um autor bastante cioso de sua nacionalidade (inclusive do colonialismo francês), a obra recentemente publicada ilumina o estudo do (inter)nacionalismo e das nações como filhas das trocas entre si e da moderna internacionalidade. Sem dúvida, se publicada em vida, teria, há muito, contribuído para o avanço de diversos debates.

\section{REFERÊNCIAS}

ANDERSON, B. Comunidades imaginadas. Lisboa: Edições 70, 2005.

BAUER, O. La cuestión de las nacionalidades y la socialdemocracia. Cidade do México: Siglo Veintiuno, 1979.

DURKHEIM, E. As regras do método sociológico. São Paulo: Martins Fontes, 2003.

MAQUIAVEL, N. O Príncipe. São Paulo: Martins Fontes, 2011. 
MARX, K.; ENGELS, F. O manifesto comunista. In: COUTINHO, C. N. et al. O manifesto comunista 150 anos depois. São Paulo: Fundação Perseu Abramo, 1998. p. $07-41$. 

